\title{
Um mapeamento sistemático sobre o uso de tecnologias digitais na Educação Infantil
}

\author{
A systematic mapping on the of digital technologies in early Childhood Education \\ Un mapeo sistemático sobre el uso de las tecnologías digitales em la Educación Infantil
}

Recebido: 13/08/2021 | Revisado: 28/08/2021 | Aceito: 24/08/2021 | Publicado: 25/08/2021

\author{
Digilaini Machado dos Santos \\ ORCID: https://orcid.org/0000-0002-7161-0741 \\ Universidade do Estado de Santa Catarina, Brasil \\ E-mail: digilaini.santos@universo.univates.br \\ Jéssica Andressa Berns Barbieri \\ ORCID: https://orcid.org/0000-0001-6859-0412 \\ Universidade do Estado de Santa Catarina, Brasil \\ E-mail: jeeh_beerns@hotmail.com \\ Célio Joaquim dos Santos \\ ORCID: https://orcid.org/0000-0002-0369-7443 \\ Universidade do Estado de Santa Catarina, Brasil \\ E-mail: celio.joaquim@yahoo.com.br \\ Adilson Vahldick \\ ORCID: https://orcid.org/0000-0002-0442-3735 \\ Universidade do Estado de Santa Catarina, Brasil \\ E-mail: adilson.vahldick@udesc.br
}

\begin{abstract}
Resumo
Este artigo é resultante de uma pesquisa do curso de Licenciatura em Informática, pela Universidade do Estado de Santa Catarina - UDESC, cujo objetivo foi conhecer as metodologias e estratégias utilizadas com as tecnologias digitais para a mediação pedagógica da aprendizagem e do desenvolvimento das crianças na Educação Infantil. A pesquisa partiu da premissa de que as crianças pequenas já têm contato com as tecnologias no contexto social, e, com apenas um toque na tela, a criança brinca, interage e (trans)forma seu modo de pensar, de agir e de relacionar-se. Com base nessa perspectiva, levantou-se o seguinte problema de pesquisa: Como as tecnologias digitais estão sendo usadas para favorecer a aprendizagem e o desenvolvimento das crianças na Educação Infantil? Quanto aos procedimentos metodológicos, é apresentada uma pesquisa qualitativa, por meio de levantamento bibliográfico e tendo como procedimento um Mapeamento Sistemático de Literatura, com base em Demerval et al. (2019). Os resultados demonstram que existe uma lacuna entre o professor e as tecnologias digitais, e, consequentemente, sua inserção nos contextos de Educação Infantil ainda é fragilizada, não sendo compreendida como um recurso potencializador de aprendizagem e desenvolvimento infantil. A ausência de formação continuada dos professores é fator relevante para a resistência à utilização de recursos tecnológicos. Por outro lado, há pesquisas que enaltecem e destacam como as tecnologias digitais podem ser utilizadas na prática pedagógica, deixando que as crianças sejam autoras e protagonistas do ato de ensinar e aprender.
\end{abstract}

Palavras-chave: Educação infantil; Tecnologias digitais; Aprendizagem e desenvolvimento; Formação continuada.

\begin{abstract}
This article is resulting from a research of the Licentiate Degree in Informatics, by the State of Santa Catarina University - UDESC, which goal was to know the methodologies and strategies used with digital technologies for the pedagogical mediation of learning and developing of Early Childhood Education children. The research started from the premise that young children already have contact with technologies in the social context, and, with just a touch on the screen, the child plays, interacts and (trans)forms their way of thinking, acting and relating with others. Based on this perspective, the following research problem was raised: How are digital technologies being used to favor the learning and development of children in Early Childhood Education? As methodological procedures, a qualitative research is presented, through a bibliographic survey and having as procedure a Systematic Literature Mapping, based on Demerval et al. (2019). The results show that there is a gap between the teacher and the digital technologies, and, consequently, their insertion in the context of Early Childhood Education is still weakened, not being understood as a potential resource for child learning and developing. The lack of continuing education for teachers is a relevant factor for resistance to the use of technological resources. On the other hand, there are studies that highlight how digital technologies can be used in pedagogical practices, allowing children to be authors, protagonists in the act of teaching and learning.
\end{abstract}

Keywords: Early childhood education; Digital technologies; Learning and development; Continuing education. 


\begin{abstract}
Resumen
Este artículo es resultado de una investigación de la Licenciatura en Informática, de la Universidad Estadual de Santa Catarina - UDESC, cuyo objetivo fue conocer las metodologías y estrategias utilizadas con tecnologías digitales para la mediación pedagógica del aprendizaje y el desarrollo de los niños en la Educación Infantil. La investigación partió de la premisa de que los niños pequeños ya tienen contacto con las tecnologías en el contexto social y, con solo un toque en la pantalla, el niño juega, interactúa y (trans)forma su modo de pensar, actuar y relacionarse. A partir de esta perspectiva, se planteó el siguiente problema de investigación: ¿Cómo se están utilizando las tecnologías digitales para favorecer el aprendizaje y desarrollo de los niños en la Educación Infantil? En cuanto a los procedimientos metodológicos, se presenta una investigación cualitativa, mediante levantamiento bibliográfico y teniendo como procedimiento un Mapeo Sistemático de la Literatura, basado en Demerval et al. (2019). Los resultados muestran que existe una brecha entre el docente y las tecnologías digitales y, en consecuencia, su inserción en el contexto de la Educación Infantil aún se ve debilitada, no siendo entendida como un recurso potencial para el aprendizaje y el desarrollo infantil. La falta de formación continua de los docentes es factor relevante de resistencia al uso de recursos tecnológicos. Por otro lado, existen estudios que resaltan cómo las tecnologías digitales pueden ser utilizadas en la práctica pedagógica, permitiendo que los niños sean autores y protagonistas en el acto de enseñar y aprender.
\end{abstract}

Palabras clave: Educación infantil; Tecnologías digitales; Aprendizaje y desarrollo; Educación continua.

\title{
1. Introdução
}

"As estruturações do instituído provocam efeitos nos afazeres, que podem seguir características estáticas, congelantes, engessadas ou seguir características que fazem nascer o extraordinário do ordinário na vida de todos os dias" (Martins Filho, 2020, p. 83).

Iniciar este trabalho com as palavras do professor Altino Martins Filho (2020) permite abrir caminhos para uma reflexão acerca de como pode ser o ato de ensinar e aprender, com práticas engessadas ou com oportunidades para transformar o ordinário em extraordinário na vida cotidiana das crianças. Com o intuito de transformar e de potencializar os processos de aprendizagem e desenvolvimento das crianças de Educação Infantil, a temática nasce e cria robustez, principalmente aliada ao uso de tecnologias digitais. Isso por entender que as tecnologias digitais fazem parte do dia a dia das crianças, mas sua relação no contexto educacional ainda é distante e, muitas vezes, ausente.

Sendo assim, as práticas pedagógicas de Educação Infantil necessitam promover experiências e vivências em que os recursos tecnológicos estejam à disposição das crianças e dos professores, para que juntos possam explorar o mundo à sua volta. Os aparatos tecnológicos não precisam ser de ponta, mas necessitam impulsionar a criação e a autonomia das crianças, sem que elas precisem pedir licença a cada minuto para emancipar-se. Para tanto, faz-se necessário olhar para as tecnologias não somente como forma de entretenimento, mas, também, como transformação do ato de ensinar e aprender.

Nesse sentido, este artigo apresenta uma visão geral de pesquisas que envolvem o uso de tecnologias digitais nos processos de aprendizagem e desenvolvimento de crianças na Educação Infantil. Sabendo da necessidade da criança de ser protagonista em suas experiências e descobertas, e considerando a necessidade de inserir e perceber as tecnologias digitais como aliadas à prática pedagógica, levantou-se como problema de pesquisa: Como as tecnologias digitais estão sendo usadas para favorecer a aprendizagem e o desenvolvimento das crianças na Educação Infantil? Como objetivo geral, buscou-se conhecer as metodologias e estratégias que estão sendo utilizadas com as tecnologias digitais para a mediação pedagógica da aprendizagem e do desenvolvimento das crianças na Educação Infantil.

$\mathrm{O}$ artigo foi organizado em cinco seções. Na primeira, apresenta-se uma breve introdução, que aborda a temática proposta por esta pesquisa. A segunda seção é constituída pela revisão de literatura, que apresenta os conceitos históricos e pedagógicos da e na Educação Infantil, tendo em vista que é a primeira etapa da Educação Básica e tem como eixos norteadores as interações e as brincadeiras. Esta seção também aborda uma breve contextualização da importância das tecnologias no contexto educacional. A terceira seção é caracterizada pelos aspectos metodológicos que sustentaram o caminhar no desenvolvimento deste trabalho. A quarta seção apresenta a análise dos dados, constituída pelo Mapeamento 
Sistemático de Literatura (MSL), com base em Demerval et al. (2019). Por fim, a última seção é organizada por meio das considerações finais, traçando e entrelaçando alguns olhares em relação às tecnologias digitais no contexto de Educação Infantil.

\section{Conceitos Históricos e Pedagógicos da Educação Infantil e o Uso das Tecnologias}

Para adentrar na temática proposta neste trabalho, faz-se necessário perpassar primeiramente pela trajetória da Educação Infantil, a fim de entender que é um segmento com especificidades diferentes das demais etapas da Educação Básica. Conhecer essa particularidade é essencial para a reflexão da inserção das tecnologias na Educação Infantil.

Assim, a criança nem sempre foi considerada pela sociedade como um sujeito social e de direitos, sendo na Idade Média confundida com um adulto em miniatura. $\mathrm{O}$ conceito de criança surge na modernidade, com a sociedade capitalista, na qual a criança começa a ser considerada como um sujeito social e cidadão de direitos. Para Walter (1984) apud Quintero (2009, p. 19), a criança “(...) não é uma miniatura cosmos adultos; bem pelo contrário, um ser humano de pouca idade que constrói o próprio universo".

Sob esse olhar de transformação, a criança passa a ser compreendida como aquela que produz cultura, cria e ressignifica suas relações com o outro e com o mundo à sua volta. Com isso, a educação das crianças passa a ser de responsabilidade não só da família, mas também do Estado. Conforme Leite Filho e Nunes (2013, p. 71), a “(...) educação das crianças, concebida, antes, como amparo e assistência, passou a configurar como direito do cidadão e dever do Estado, numa perspectiva educacional, em respostas a movimentos sociais em defesa dos direitos das crianças".

Diante desse contexto, o Brasil apresentou avanços significativos a partir da Constituição Federal de 1988, com o Estatuto da Criança e do Adolescente (ECA), instituída pela Lei 8.069/90, e, na sequência, com a nova Lei de Diretrizes e Bases (LDB), 9394/96, que coloca a Educação Infantil como primeira etapa da Educação Básica, atendendo crianças de 0 a 5 anos de idade. Assim, a LDB 9394/96 destaca que "a educação infantil, primeira etapa da educação básica, tem como finalidade o desenvolvimento integral da criança de até 5 (cinco) anos, em seus aspectos físico, psicológico, intelectual e social, complementando a ação da família e da comunidade" (Brasil, 1996, texto digital). Nesse aspecto, as políticas públicas para a Educação Infantil surgiram para dar apoio e orientações às práticas pedagógicas desenvolvidas com as crianças de 0 a 5 anos de idade. Dessa forma, o cuidar e o educar fazem parte de todas as políticas adotadas para atender as crianças de Educação Infantil, desvinculando a ideia de assistencialismo que perpetuou por muito tempo na sociedade. Diante do exposto, não basta somente cuidar, é preciso criar oportunidades para que a criança se desenvolva de forma integral e, nesse sentido, as interações e brincadeiras são destacadas nos documentos como eixos norteadores das práticas docentes, conforme destacam as Diretrizes Curriculares Nacionais para a Educação Infantil - DCNEI (Brasil, 2009, p. 18):

A proposta pedagógica das instituições de Educação Infantil deve ter como objetivo garantir à criança acesso a processos de apropriação, renovação e articulação de conhecimentos e aprendizagens de diferentes linguagens, assim como o direito à proteção, à saúde, à liberdade, à confiança, ao respeito, à dignidade, à brincadeira, à convivência e à interação com outras crianças.

As DCNEI (Brasil, 2009) apresentam a criança como um sujeito histórico, cidadão de direitos, que aprende por meio das interações e das relações que constrói com o outro e com o mundo. A partir disso, constrói sua identidade pessoal e coletiva, que se dá por meio de diferentes linguagens, através das quais ela imagina, fantasia, expressa desejos e sentimentos, questiona sentido e significado sobre o universo em que está inserida, (re)produzindo cultura, o que a leva a aprender a aprender. 
Nesse sentido, as DCNEI (Brasil, 2009) enfatizam que a prática pedagógica das crianças necessita estar sustentada nas interações e brincadeiras, por fazer parte do mundo infantil, além de serem os eixos que promovem a aprendizagem das crianças. Corroborando com as diretrizes, a Base Nacional Comum Curricular - BNCC (Brasil, 2017) organiza o novo currículo para a Educação Infantil, apresentando que as crianças têm o direito de conviver, brincar, participar, explorar, expressar, conhecer-se, sendo elas autoras na busca pelo conhecimento. Referente aos direitos de aprendizagem, a BNCC (Brasil, 2017, p. 40) menciona que é essencial:

- Conviver com outras crianças e adultos, em pequenos e grandes grupos, utilizando diferentes linguagens, ampliando o conhecimento de si e do outro, o respeito em relação à cultura e às diferenças entre as pessoas.

- Brincar cotidianamente de diversas formas, em diferentes espaços e tempos, com diferentes parceiros (crianças e adultos), ampliando e diversificando seu acesso a produções culturais, seus conhecimentos, sua imaginação, sua criatividade, suas experiências emocionais, corporais, sensoriais, expressivas, cognitivas, sociais e relacionais.

- Participar ativamente, com adultos e outras crianças, tanto do planejamento da gestão da escola e das atividades propostas pelo educador quanto da realização das atividades da vida cotidiana, tais como a escolha das brincadeiras, dos materiais e dos ambientes, desenvolvendo diferentes linguagens e elaborando conhecimentos, decidindo e se posicionando.

- Explorar movimentos, gestos, sons, formas, texturas, cores, palavras, emoções, transformações, relacionamentos, histórias, objetos, elementos da natureza, na escola e fora dela, ampliando seus saberes sobre a cultura, em suas diversas modalidades: as artes, a escrita, a ciência e a tecnologia.

- Expressar, como sujeito dialógico, criativo e sensível, suas necessidades, emoções, sentimentos, dúvidas, hipóteses, descobertas, opiniões, questionamentos, por meio de diferentes linguagens.

- Conhecer-se e construir sua identidade pessoal, social e cultural, constituindo uma imagem positiva de si e de seus grupos de pertencimento, nas diversas experiências de cuidados, interações, brincadeiras e linguagens vivenciadas na instituição escolar e em seu contexto familiar e comunitário.

Para promover esses direitos, é necessário lançar mão de várias estratégias e metodologias para que sejam promovidos nos contextos de Educação Infantil, qualificando a vida cotidiana das crianças. O documento também apresenta a organização curricular para a Educação Infantil conforme os campos de experiências, sendo eles: a) Eu, o outro e nós: a finalidade é a criança valorizar sua própria identidade, ao mesmo tempo em que respeita e valoriza a diversidade vivenciada no contexto social; b) Corpo, gestos e movimentos: o intuito é promover oportunidades em que as crianças, por meio do seu corpo, dos sentidos, dos gestos e dos movimentos, construam seu conhecimento, estabelecendo relações com o mundo à sua volta; c) Traços, cores, sons e formas: o objetivo é oportunizar as diferentes manifestações artísticas, culturais e científicas, locais e universais, no cotidiano da Educação Infantil, vivenciando diferentes formas de expressão e linguagens; d) Escuta, fala, pensamento e imaginação: o propósito é criar situações comunicativas das quais as crianças participem e nas quais interajam com as pessoas em seu entorno, potencializando o desenvolvimento das múltiplas linguagens; e) Espaços, tempos, quantidades, relações e transformações: a finalidade é oferecer meios para que as crianças possam criar seus problemas, observações, explorando, manipulando, criando hipóteses e soluções para consultar e sanar suas dúvidas e curiosidades (Brasil, 2017).

Perpassando pela trajetória da Educação Infantil, conhecendo os aspectos necessários para que ela se desenvolva de forma integral, fica evidente que o adulto necessita aproximar da realidade da criança o ato de ensinar e aprender. Para tanto, é preciso romper com metodologias que engessam esses processos, com formas mecanizadas e padronizadas de promover o conhecimento. Como aponta Freire (1996, p. 27), "ensinar não é transferir conhecimento, mas criar possibilidades para sua produção ou para sua construção".

Sob esse olhar, entende-se que as crianças estão imersas em um mundo que é completamente rodeado pelas tecnologias digitais. Por isso, compreende-se que esses recursos possam ser aliados às (trans)formações do ato de ensinar e aprender. Porém, para que isso aconteça, os professores precisam compreender que as tecnologias têm um potencial muito maior do que simplesmente transmitir o conteúdo. Sobre isso, Kenski (2007, p. 66) ressalta que, "na maioria das vezes, esses 
profissionais do ensino estão mais preocupados em usar as tecnologias que têm a sua disposição para "passar o conteúdo", sem se preocupar com o aluno, aquele que precisa aprender".

Nesse sentido, compreende-se que as tecnologias podem e necessitam ser utilizadas nos contextos de Educação Infantil, desde a mais tenra idade, tendo em vista que podem potencializar as experiências e descobertas das crianças pequenas. Assim, Kenski (2007, p. 78) corrobora, enfatizando que "a escola deve, antes, pautar-se pela intensificação das oportunidades de aprendizagem e autonomia dos alunos em relação à busca de conhecimentos, da definição de seus caminhos, da liberdade para que possam criar oportunidades e serem os sujeitos da própria existência".

Kenski (2007) intensifica a necessidade da escola e dos professores de promover um aprendizado prazeroso, atraente e divertido, para aguçar a curiosidade das crianças pequenas em serem autoras na busca pelo próprio conhecimento. Por meio dessa compreensão, a inserção de artefatos culturais em novas tecnologias digitais na Educação Infantil pode significar um grande avanço cultural, abrindo caminhos para a equidade nos processos de ensino e aprendizagem. Com isso, o autor destaca que:

Dessa forma, as inovações tecnológicas podem contribuir de modo decisivo para transformar a escola em um lugar de exploração de culturas, de realização de projetos, de investigação e debate. Educar para a inovação e a mudança significa planejar e implantar propostas dinâmicas de aprendizagem, em que se possam exercer e desenvolver concepções sócio-históricas da educação - nos aspectos cognitivo, ético, político, científico, cultural, lúdico e estético - em toda a sua plenitude e, assim, garantir a formação de pessoas para o exercício da cidadania e do trabalho com liberdade e criatividade (Kenski, 2007, p. 79).

O desafio é inventar e descobrir usos criativos da tecnologia educacional que inspirem o desenvolvimento da criatividade, da imaginação criadora, da sensibilidade tátil, visual, entre outras, ou seja, que as crianças pequenas possam ter oportunidades de criar e desenvolver suas múltiplas linguagens dentro e fora da escola. Dessa forma, o respeito às diferenças e necessidades das crianças pequenas são aspectos fundamentais, que necessitam ser contemplados e potencializados pelos professores.

Portanto, é imprescindível que os professores sejam observadores constantes do ato de ensinar e aprender, escutando as crianças pequenas, com a finalidade de buscar novas metodologias que as possibilitem explorar, experimentar e descobrir o novo, com autonomia e alteridade.

\section{Metodologia}

Para verificar que metodologias e/ou estratégias estão sendo utilizadas pelos professores e com as crianças para agregar as tecnologias digitais aos processos de aprendizagem e desenvolvimento, adotou-se uma pesquisa qualitativa. Segundo Minayo (2001, p. 22), a pesquisa qualitativa "trabalha com o universo de significados, motivos, aspirações, crenças, valores e atitudes, o que corresponde a um espaço mais profundo das relações, dos processos e dos fenômenos", os quais não podem ser quantificados.

Quanto aos procedimentos da pesquisa, utiliza-se pesquisa bibliográfica mediante o MSL (Demerval et al., 2019). A pesquisa bibliográfica "permite que o pesquisador fique frente a frente com diferentes autores envolvidos com a temática proposta. Esse esforço em discutir ideias e pressupostos tem como lugar privilegiado de levantamento as bibliotecas, os centros especializados e arquivos" (Minayo, 2001, p. 53).

Referente ao MSL, Demerval et al. (2019) contribui ao destacar que esse método permite categorizar estudos existentes sobre determinado tema, quantificando os resultados encontrados. O MSL possui três etapas: planejamento, condução e relatório. Na etapa de planejamento, é elaborado e avaliado o protocolo de pesquisa. Na etapa de condução, a busca é realizada, sucedida pela seleção dos artigos e por sua triagem, através da leitura de seus resumos, introduções e conclusões, 
para serem comparados aos critérios de inclusão e exclusão. A última etapa é caracterizada pelos resultados levantados pelo MSL, na qual os artigos são associados às questões de pesquisa.

Sendo assim, para contemplar o objetivo geral, que é fornecer uma visão geral de pesquisas que envolvem o uso de tecnologias digitais nos processos de ensino e aprendizagem com crianças pequenas no Brasil, foram criadas questões norteadoras que delinearam o caminho da pesquisa. As questões, dispostas no Quadro 1, corroboraram com o propósito de verificar artigos que utilizam estratégias e metodologias de ensino e aprendizagem com as crianças pequenas no Brasil.

Quadro 1 - Questões.

QP1: Quais tecnologias digitais estão sendo utilizadas nos contextos de Educação Infantil para favorecer os processos
de ensino e aprendizagem?
QP2: Quais as metodologias elou estratégias estão sendo usadas para ofertar as tecnologias às crianças pequenas?
QP3: Quais as dificuldades e ou possibilidades apresentadas com o uso das tecnologias digitais nos processos de ensino
e aprendizagem?

Fonte: Autores (2020).

A pesquisa foi realizada nos meses de março e abril de 2021. O protocolo de pesquisa é apresentado no Quadro 2, exposta na sequência.

Quadro 2 - Protocolo de pesquisa.

\begin{tabular}{|l|l|}
\hline Bases de dados & Google Acadêmico e Periódicos da CAPES \\
\hline String de busca & “'mídias digitais" OU "tecnologias digitais") AND "Educação Infantil”" \\
\hline Critérios de inclusão & $\checkmark$ Artigos completos publicados nos últimos 10 anos; \\
& $\checkmark$ Artigos que abordaram o uso de tecnologias; \\
& $\checkmark$ Artigos que possibilitam a seleção de metodologias eestratégias na inserção das tecnologias \\
& na Educação Infantil; \\
& $\checkmark$ Artigos que apresentam os prós e contras do uso das tecnologias na educação; \\
& $\checkmark$ Artigos completos e publicados em revistas que enfatizam o uso das tecnologias no contexto de \\
& Educação Infantil. \\
\hline Critérios de exclusão & $\checkmark$ A experiência não foi realizada no Brasil; \\
& $\checkmark$ Artigos duplicados; \\
& $\checkmark$ Artigos em que a experiência está articulada com o ensino fundamental; \\
& $\checkmark$ Artigos cuja experiência não esteja voltada para as crianças pequenas; \\
& $\checkmark$ Resumos expandidos, TCCs, dissertações, teses, que não estejam em formato de artigo e \\
& publicados em revistas, congressos ou simpósios e/ou que estejam sem o ano de publicação. \\
\hline
\end{tabular}

Fonte: Autores (2020).

Com isso, iniciou-se no mês de março de 2021 o processo de busca, por meio do Google Scholar e do portal de Periódicos da CAPES. Ambos os bancos de dados possibilitam o acesso a literaturas acadêmicas nas diversas áreas do conhecimento, além de pesquisas em eventos e revistas nacionais e internacionais. Para otimizar o resultado da pesquisa, foi estabelecida a seguinte string de busca: ("mídias digitais" OU "tecnologias digitais") AND "Educação Infantil”. Ao longo do processo de inclusão, foi possível estabelecer um quantitativo total de 106 pesquisas encontradas por meio do Google Scholar. Nos periódicos da CAPES, foi destacado um quantitativo de duas pesquisas, as quais estavam repetidas na primeira busca. A Figura 1 sintetiza esse processo. 
Figura 1 - Processo de busca no Google Scholar e nos Periódicos da CAPES.

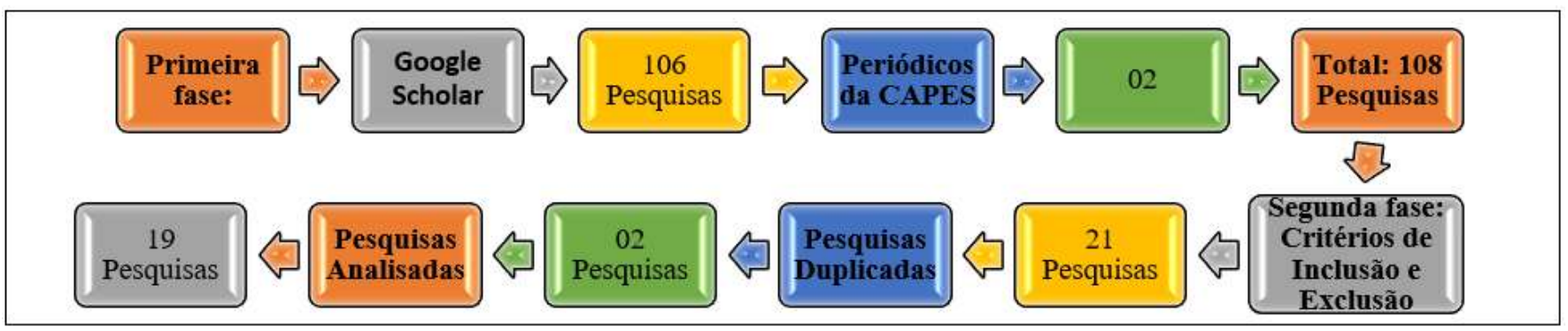

Fonte: Autores (2021).

\section{Resultados e Discussão dos Dados}

Esta seção apresenta os resultados da pesquisa, os quais foram analisados e classificados em consonância com as questões norteadoras apresentadas neste trabalho. Para a análise das pesquisas, é necessário, primeiramente, conhecê-las, mesmo que de forma breve. Assim, no Quadro 3 encontram-se as pesquisas selecionadas.

Quadro 3 - Artigos selecionados.

\begin{tabular}{|c|c|c|c|}
\hline \multicolumn{4}{|c|}{ Mídias digitais na Educação Infantil } \\
\hline $\mathbf{N}^{\circ}$ & Autor & $\begin{array}{r}\text { Título } \\
\end{array}$ & Ano \\
\hline 1 & $\begin{array}{l}\text { Fernanda Câmpera Clímaco } \\
\text { Claudio Marcio Magalhaes }\end{array}$ & $\begin{array}{l}\text { Educação Infantil, mídias digitais e práticas educativas: caminhos } \\
\text { cruzados, possíveis diálogos }\end{array}$ & 2017 \\
\hline 2 & $\begin{array}{c}\text { Mahara Canaan } \\
\text { Luciana Ribeiro } \\
\text { Yuki Paolla } \\
\end{array}$ & $\begin{array}{l}\text { Tecnologias digitais e influências no desenvolvimento das } \\
\text { crianças }\end{array}$ & 2017 \\
\hline 3 & Nataly Cordeiro de Abreu Cabral et al. & $\begin{array}{l}\text { Jogo digital em uma proposta de sequência didática para a } \\
\text { educação infantil: avaliação sob o ponto de vista dos professores }\end{array}$ & 2018 \\
\hline 4 & Erika Alvarenga Badaró & Recursos tecnológicos na Educação Infantil & 2020 \\
\hline 5 & Leone Lebrão & Educação tecnológica no ensino infantil & 2020 \\
\hline 6 & Heloisa Aparecida Candido Miquelino & $\begin{array}{l}\text { Os recursos tecnológicos e o desenvolvimento da linguagem na } \\
\text { Educação Infantil }\end{array}$ & 2020 \\
\hline 7 & $\begin{array}{l}\text { Patrick Salazar da Silva } \\
\text { Joice Araújo Esperança }\end{array}$ & $\begin{array}{l}\text { Mídias digitais e Educação Infantil: construindo possibilidades } \\
\text { pedagógicas. }\end{array}$ & 2020 \\
\hline \multicolumn{4}{|c|}{ Tecnologias digitais na Educação Infantil } \\
\hline $\mathbf{N}^{\mathbf{o}}$ & Autor & $\begin{array}{ll}\text { Título } \\
\end{array}$ & Ano \\
\hline 1 & Patrícia Lisboa & $\begin{array}{l}\text { Os softwares educativos e a construção de habilidades cognitivas } \\
\text { na pré-escola }\end{array}$ & 2013 \\
\hline 2 & $\begin{array}{c}\text { Carmela de Araújo } \\
\text { Maria de Fátima Reszka }\end{array}$ & O brincar, as mídias e as tecnologias digitais na Educação Infantil & 2016 \\
\hline 3 & $\begin{array}{l}\text { Maria Auricélia da Silva } \\
\text { José Aloísio Macedo Filho } \\
\text { José Aires de Castro Filho }\end{array}$ & $\begin{array}{l}\text { Histórias Fantásticas: produção de textos com suporte digital na } \\
\text { Educação Infantil }\end{array}$ & 2017 \\
\hline 4 & $\begin{array}{l}\text { Rosana Abutakka V. dos Anjos } \\
\text { Kátia Morosov Alonso } \\
\text { Alexandre Martins dos Anjos }\end{array}$ & $\begin{array}{c}\text { Infância (des)conectada e a psicopedagogia: o uso das } \\
\text { tecnologias digitais na educação infantil e o impacto na } \\
\text { aprendizagem }\end{array}$ & 2018 \\
\hline 5 & Lucineide Cruz Araújo et al. & $\begin{array}{c}\text { Jogos digitais na Educação Infantil: contribuições para o } \\
\text { processo de aprendizagem }\end{array}$ & 2018 \\
\hline 6 & $\begin{array}{l}\text { Amanda Campelo Silva de Souza } \\
\text { Flávia Bezerra Gomes } \\
\text { Maria Auxiliadora Soares Padilha }\end{array}$ & $\begin{array}{l}\text { Perspectivas de docentes sobre o uso da mesa educacional na } \\
\text { educação infantil da rede municipal do recife: conteúdos e } \\
\text { estratégias }\end{array}$ & 2018 \\
\hline
\end{tabular}


Research, Society and Development, v. 10, n. 11, e137101119421, 2021

(CC BY 4.0) | ISSN 2525-3409 | DOI: http://dx.doi.org/10.33448/rsd-v10i11.19421

\begin{tabular}{|c|c|c|c|}
\hline 7 & Tatiane Vidal dos Reis et al. & $\begin{array}{l}\text { Tecnologias digitais na Educação Infantil: projeto de } \\
\text { aprendizagem com Google Maps e Google Street View }\end{array}$ & 2019 \\
\hline 8 & $\begin{array}{c}\text { Fernando Dandaro } \\
\text { Lidiane Silva Neves Oliveira } \\
\text { Kelly Regina de Paulo }\end{array}$ & O uso de tecnologias digitais na Educação Infantil & 2019 \\
\hline 9 & $\begin{array}{c}\text { Hanna Almeida Sousa } \\
\text { Maria Auricélia da Silva } \\
\text { José Aires de Castro Filho }\end{array}$ & $\begin{array}{l}\text { Produção e ilustração de textos como suporte digital na Educação } \\
\text { Infantil }\end{array}$ & 2019 \\
\hline 10 & Ariadne Rolli Bevilaqua & $\begin{array}{l}\text { Ensino remoto contingencial: a educação infantil na pandemia } \\
\text { em uma escola municipal do Rio de Janeiro }\end{array}$ & 2020 \\
\hline 11 & $\begin{array}{c}\text { Josélia Santana Bezerra } \\
\text { Giovane Ferreira Silva }\end{array}$ & $\begin{array}{l}\text { O uso das tecnologias digitais no ensino de matemática para os } \\
\text { alunos de educação infantil }\end{array}$ & 2020 \\
\hline 12 & $\begin{array}{l}\text { Nedia Maria de Oliveira } \\
\text { Simão Pedro Pinto Marinho }\end{array}$ & Tecnologias digitais na educação infantil: sociais de professores & 2020 \\
\hline
\end{tabular}

Fonte: Autores (2021).

Na Tabela 2, observa-se uma distribuição temporal dos estudos com maior proporção após o ano de 2017, como é possível visualizar na Figura 2.

Figura 2 - Distribuição temporal dos estudos.

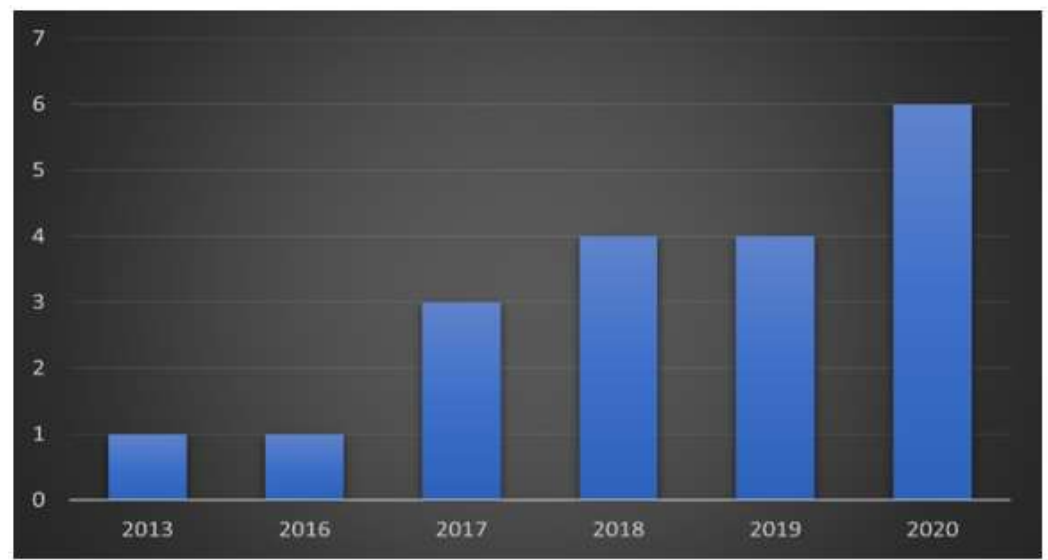

Fonte: Autores (2021).

Ao analisar os aspectos metodológicos das pesquisas, verificou-se que a maioria dos artigos apresenta uma pesquisa participante e em escola pública, o que pode ser constatado na Figura 3.

Figura 3 - Procedimentos metodológicos apontados nas pesquisas.

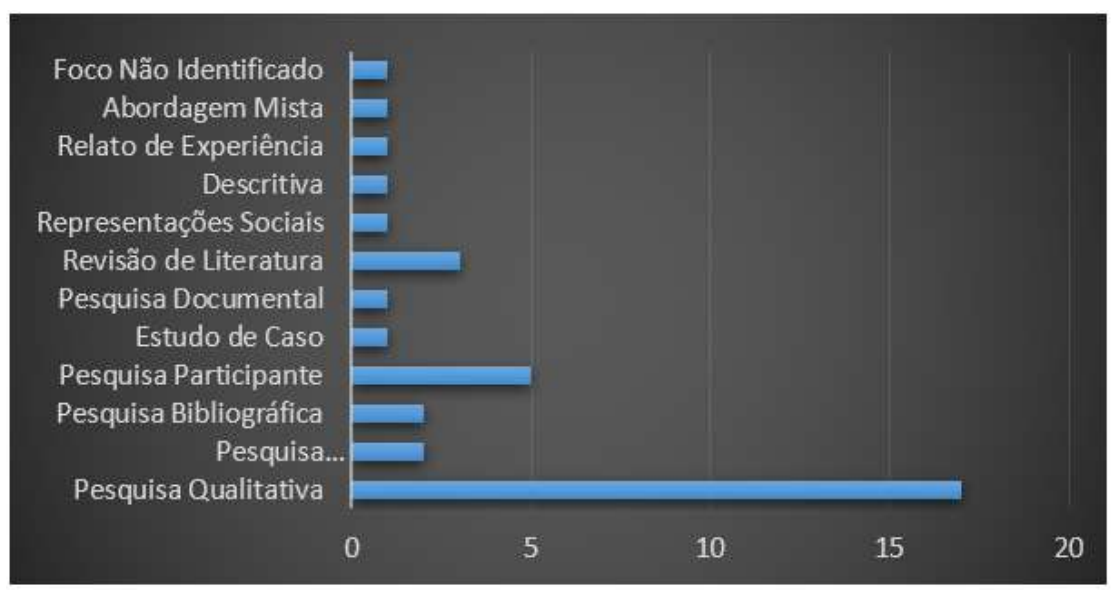

Fonte: Autores (2021). 
Os instrumentos de pesquisa podem ser observados na Figura 4. É importante salientar que muitas investigações utilizaram mais do que um instrumento para a produção dos dados, sendo a junção do questionário com a entrevista. Da mesma forma, houve aquelas em que não foi possível identificar os instrumentos utilizados, sendo estas pesquisas de caráter bibliográfico ( 3 pesquisas), baseadas em revisão de literatura (3 pesquisas) e em relatos de experiências ( 2 pesquisas).

Figura 4 - Instrumentos utilizados pelas pesquisas para a produção dos dados.

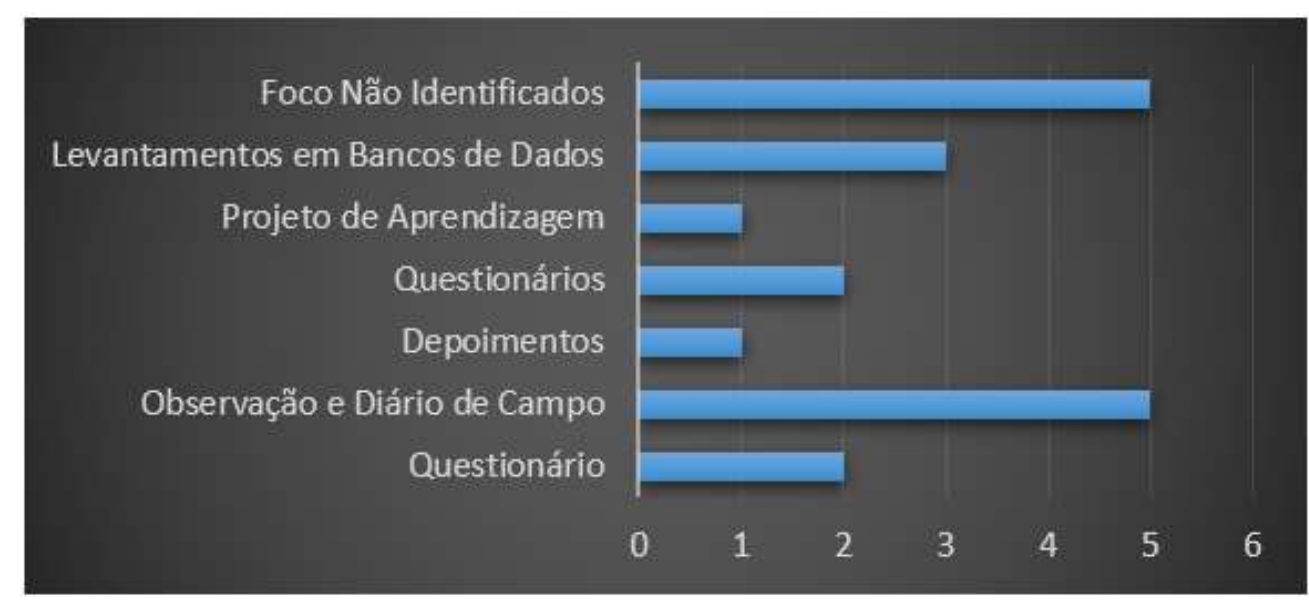

Fonte: Autores (2021).

Ressalta-se, ainda, que as pesquisas ficaram centradas mais nas escolas públicas, conforme a Figura 5. Também é necessário mencionar que outras pesquisas não forneceram esses dados, podendo também ser observadas na Figura 5.

Figura 5 - Escolas pesquisadas.

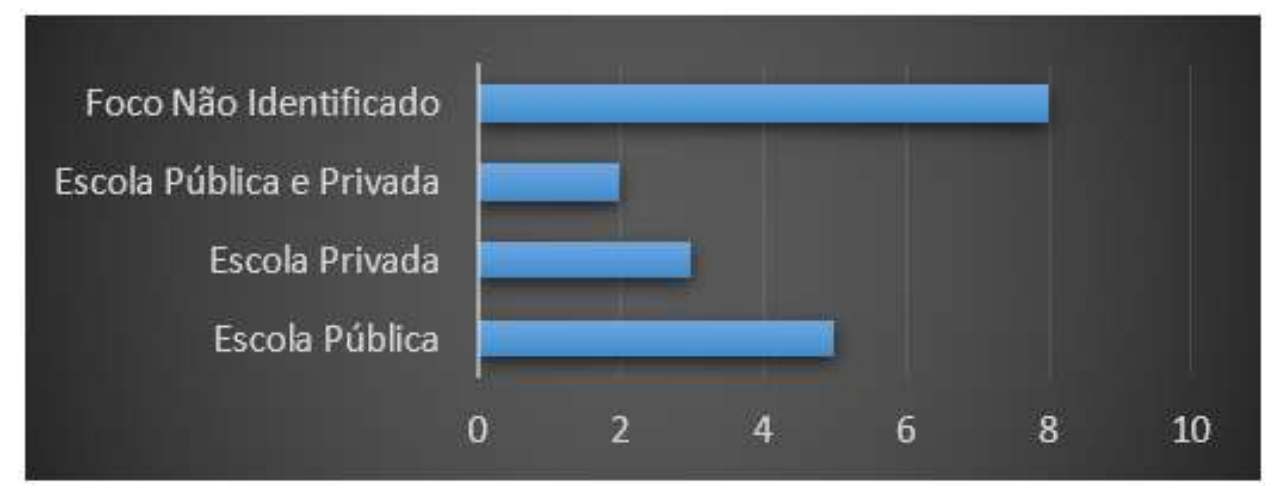

Fonte: Autores (2021).

É importante salientar que os trabalhos de Araújo e Reszka (2016) e de Cabral et al. (2018) apresentam suas pesquisas em escolas públicas e privadas. Com isso, foi possível perceber uma distribuição maior de recursos tecnológicos na escola privada, sendo que os recursos das escolas públicas ficaram mais centrados no aparelho de som e na televisão.

Referente ao público-alvo, todas as pesquisas estavam concentradas na Educação Infantil, porém, o público-alvo varia entre professores, famílias e crianças, conforme a Figura 6. Quando direcionadas para as crianças, contemplam, na maior parte, a faixa etária dos 5 anos, também conforme a Figura 6. 
Figura 6 - Público-alvo.

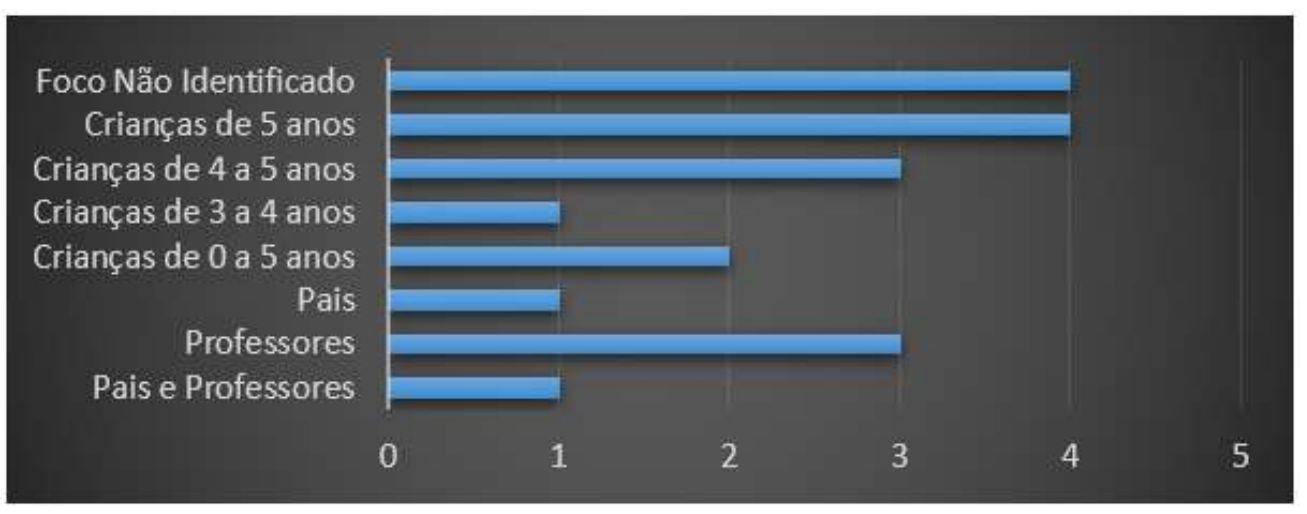

Fonte: Autores (2021).

No que tange à QP1: Quais tecnologias digitais estão sendo utilizadas nos contextos de Educação Infantil para favorecer os processos de ensino e aprendizagem? pode-se observar que as publicações evidenciam que as escolas têm recursos tecnológicos diversificados (Figura 7) à disposição.

Figura 7 - Recursos tecnológicos disponíveis nos contextos de Educação Infantil.

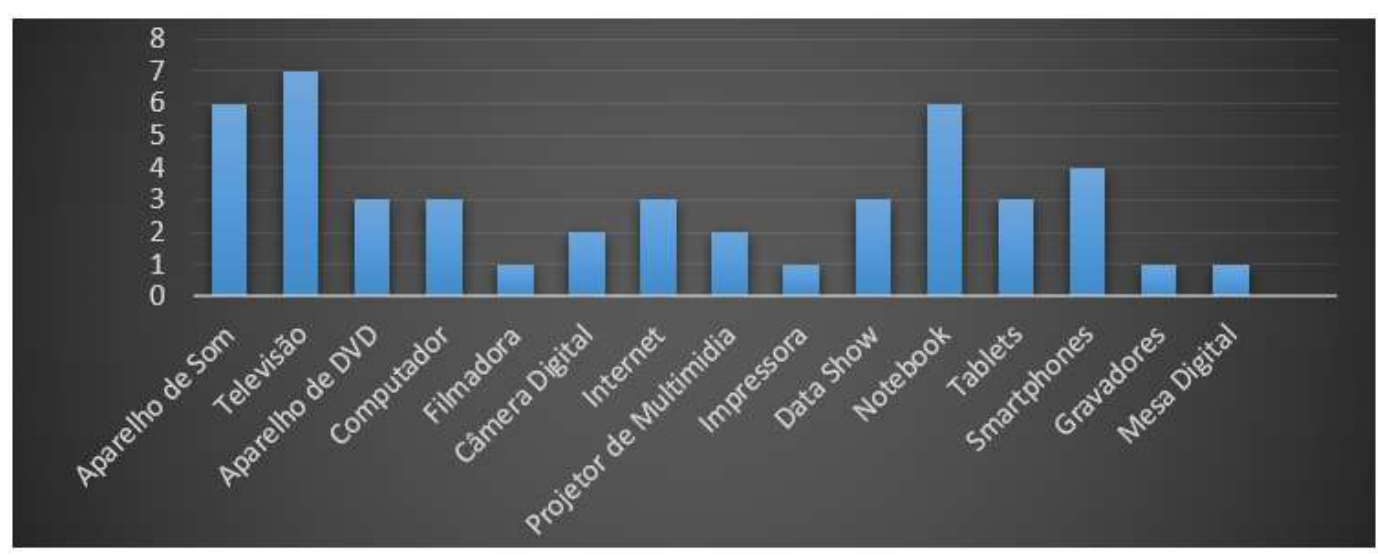

Fonte: Autores (2021).

Os trabalhos analisados apresentam, em sua maioria, escolas com apenas dois tipos de equipamentos tecnológicos, o aparelho de som e a televisão, o que limita o uso das tecnologias na Educação Infantil. Por outro lado, existem aquelas escolas que possuem mais do que três tipos de equipamentos e com internet disponível para as crianças e professores, e que, mesmo assim, não conseguem inserir esses recursos em sua prática pedagógica. Diante disso, Araújo e Renska (2016) enfatizam que não basta ter à disposição os recursos tecnológicos, é preciso entender e inserir de maneira prática e eficaz as novas tecnologias no currículo escolar.

É importante salientar que o uso dos notebooks e smartphones utilizados pelos professores é de acesso particular dos próprios docentes, que fazem o deslocamento dos aparelhos de casa para a escola e vice-versa. Apenas Miquelino (2020) apresentou a disponibilidade de 10 notebooks para a utilização dos alunos. Com isso, percebe-se que os equipamentos tecnológicos disponíveis no contexto de Educação Infantil carecem de inovação e precisam ser mais bem utilizados pelos professores e com as crianças na prática pedagógica.

A partir da QP2: Quais as metodologias elou estratégias estão sendo usadas para ofertar as tecnologias às crianças pequenas? pode-se verificar que as metodologias e estratégias ainda são sustentadas por uma pedagogia pautada no modelo "tradicional", ou seja, vinculada a fazer as "atividades" no papel. Isso não significa que o tradicional não seja eficaz para 
algumas propostas, mas existem outros meios, outras possibilidades que se pode construir no contexto de Educação Infantil, quebrando os muros que engessam a prática docente. É preciso que o uso das tecnologias não girem em torno de si mesmo, somente como uma ferramenta técnica, mas, sim, que dê sentido e significado à construção e ao desenvolvimento das experiências das crianças. Nesse sentido, a Figura 8 apresenta as estratégias e metodologias utilizadas para aliar as tecnologias digitais à prática pedagógica.

Figura 8 - Metodologias e estratégias que utilizam as tecnologias digitais na Educação Infantil.

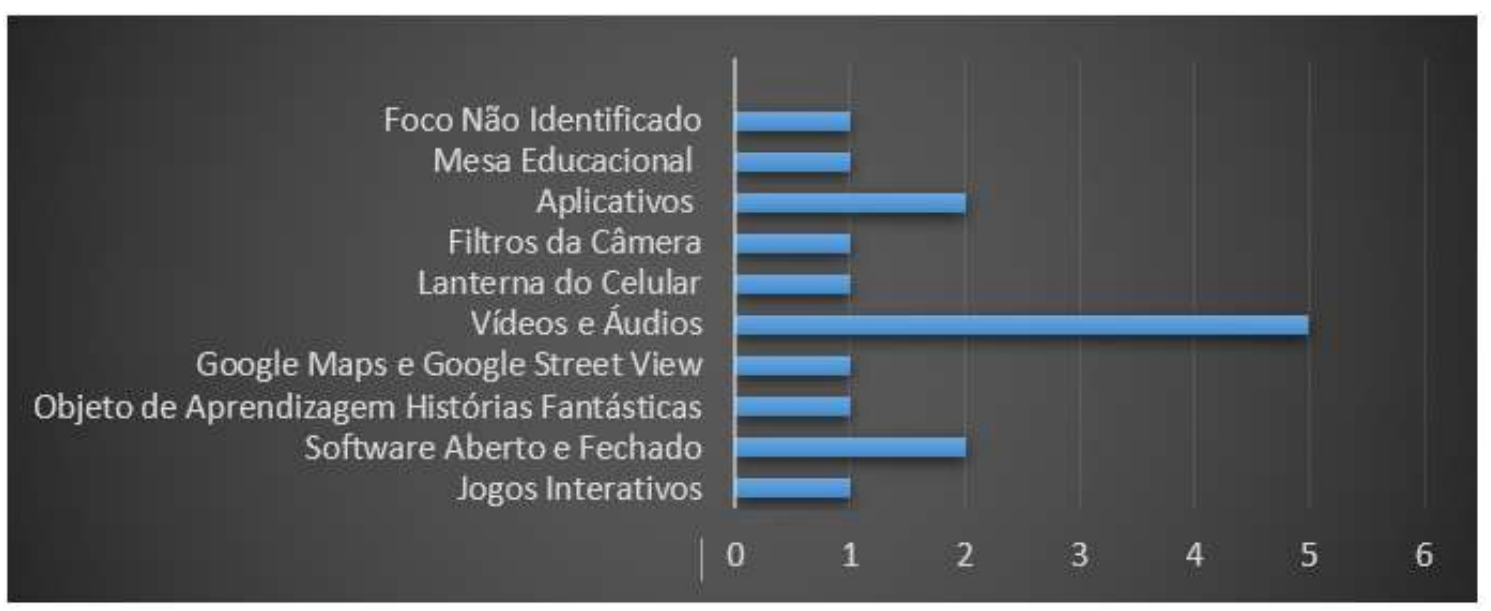

Fonte: Autores (2021).

A maioria das metodologias e estratégias propostas são apresentadas pelos pesquisadores que não são educadores nas escolas investigadas. Sob essa perspectiva, fica um questionamento: Será que essas experiências desenvolvidas com o uso das tecnologias digitais inquietam os profissionais de Educação Infantil a ponto de darem continuidade na (trans)formação do ato de ensinar e aprender? Essa indagação é necessária para que se possa refletir sobre o quanto as tecnologias digitais ainda precisam ser compreendidas pelos envolvidos com o contexto educacional.

Referente às metodologias e estratégias, apresenta-se na sequência como foram constituídas na prática pedagógica de Educação Infantil.

a) Jogos interativos: Os jogos estão sendo utilizados com o intuito de criar regras e combinados com as crianças, já que os recursos tecnológicos não contemplam o número de crianças por turma. Além disso, são sempre vinculados a reforçar um "conteúdo" e com atividades voltadas para a pré-alfabetização, já que são utilizados, normalmente, com as crianças de 5 anos.

b) Softwares abertos e fechados: Utilizados no ambiente da sala de informática. O software fechado Coelho Sabido é utilizado com o intuito de deixar a criança brincar, porém, é uma atividade repetitiva (Lisboa, 2013). Como software aberto, é possível citar o Tux Paint, em que, em um primeiro momento, a criança brinca livremente para conhecer, e depois pratica com atividades específicas que reforçam o conteúdo, normalmente voltadas para a pré-alfabetização, já que são utilizadas usualmente com as crianças de 5 anos (Lisboa, 2013).

c) Objetos de aprendizagem: As histórias fantásticas são utilizadas para contribuir com o desenvolvimento da linguagem oral e escrita, através das quais as crianças criam cenários e histórias, transcrevendo-as. É um recurso utilizado, majoritariamente, na faixa-etária dos 5 anos (Silva, Macedo Filho \& Castro Filho, 2017).

d) Google Maps e Google Street View: Estes recursos foram utilizados a partir da necessidade da criança em saber onde é a casa dela (Cabeludo). Com isso, foram organizadas e planejadas ações que englobam desde o senso comum até o conhecimento científico, traçando um mapeamento de onde cada um mora e identificando-os com a ferramenta tecnológica citada (Reis et al., 2019). 
e) Vídeos e áudios: Criados a partir do interesse da criança, sendo que elas, na hora de fazer as gravações, identificavam-se como youtubers, pedindo para que os telespectadores curtissem e se inscrevessem na página. Foram gravadas músicas cantadas no dia a dia na Educação Infantil, como conversas e histórias criadas pelas próprias crianças. Esta experiência foi criada por Silva e Esperança (2020).

f) Lanterna do celular: Foi utilizada para criar sombras e experiências com diversas cores do celofane. Esta também foi uma experiência criada pelos pesquisadores Silva e Esperança (2020) com as crianças de Educação Infantil.

g) Filtros da câmera: Utilizados com as crianças para transformar, criar novas imagens pessoais por meio dos aplicativos Instagram, Snapchat e Pokémon Go, criando personagens e efeitos gráficos diversos, com personagens diferentes temáticos e escolhidos pelas próprias crianças, citadas e experenciadas pelos pesquisadores Silva e Esperança (2020).

h) Aplicativos: Além do exposto anteriormente, também foram citados em outros trabalhos o uso do WhatsApp e do Facebook como uma forma de repassar os conteúdos e de dar suporte às famílias enquanto as aulas estavam suspensas por conta da COVID-19.

i) Mesa educacional: Utilizada por poucos professores para reforçar o conteúdo pragmático, ou seja, aquele vinculado ao currículo ou com algum jogo para entretenimento da criança. Souza, Gomes e Padilha (2018) relatam que os professores não têm conhecimento detalhado acerca dos elementos que compõem a mesa educacional, o que dificulta no momento de planejar as experiências a serem vivenciadas pelas crianças.

Diante do exposto, percebe-se que as ferramentas tecnológicas ainda são um desafio para os profissionais, sendo consideradas, na grande maioria dos relatos, somente como recursos técnicos, e não como recursos potencializadores da aprendizagem.

Em relação à QP3: Quais as dificuldades e ou possibilidades com o uso das tecnologias digitais nos processos de ensino e aprendizagem? observou-se a necessidade de romper barreias, de deixar-se permitir que o novo possa fazer parte da vida educativa de professores e crianças. Com isso, ficou visível que não basta somente inserir os recursos tecnológicos nos contextos de Educação Infantil, mais do que isso, é preciso conhecer como utilizar esses recursos para favorecer a aprendizagem e o desenvolvimento das crianças.

Diante do exposto, a Figura 9 aponta as dificuldades em relação à inserção das tecnologias digitais na Educação Infantil.

Figura 9 - Dificuldades sobre o uso das tecnologias digitais na Educação Infantil.

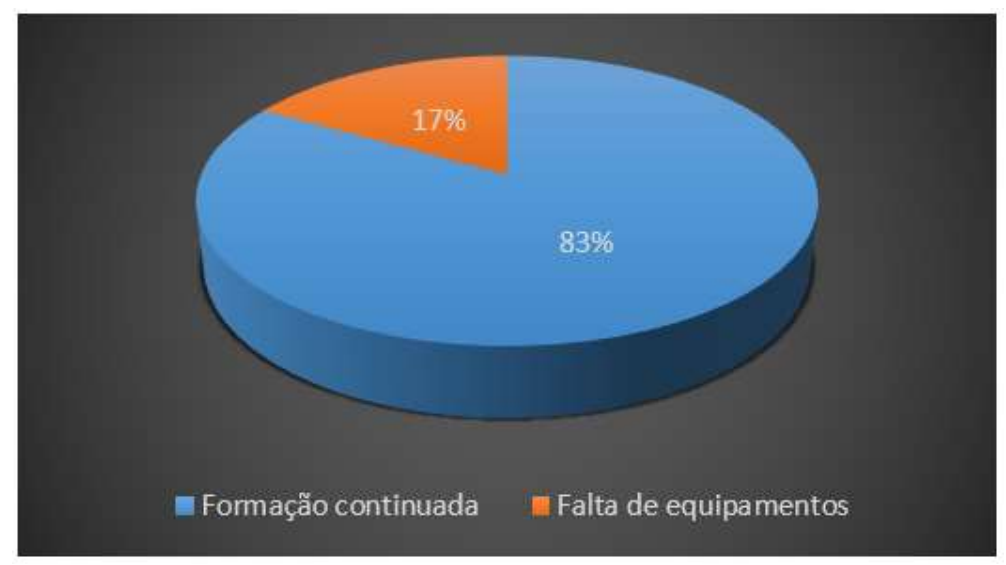

Fonte: Autores (2021).

Diante desses números, percebe-se que a falta de formação continuada dos professores acaba afetando as práticas desenvolvidas com as tecnologias digitais. É preciso compreender que a inserção das tecnologias digitais na Educação Infantil 
não é apenas para cumprir o currículo e a legislação presentes, mas para ampliar e oportunizar às crianças pequenas o direito de apropriar-se da cultura digital, ampliando seu conhecimento de mundo.

Como possibilidades, os professores reconhecem a potencialidade que as tecnologias digitais oferecem na prática pedagógica, mas a maioria não consegue inseri-las nos contextos educacionais de forma que não seja apenas para repassar ou reforçar conteúdo ou somente como um recurso técnico de uso do professor. São poucos os professores que conseguem romper com essa barreira e oferecer os recursos tecnológicos como aliados à prática pedagógica das crianças pequenas. Portanto, é visível que o uso das tecnologias digitais na Educação Infantil ainda é um desafio que precisa ser superado para fazer sentindo na vida da criança e dos profissionais na (trans)formação do ato de ensinar e aprender.

\section{Considerações Finais}

Percebeu-se, ao longo do trabalho, que os recursos tecnológicos ainda não são reconhecidos como ferramentas de aprendizagem com e para as crianças pequenas. Um fator curioso, que chama a atenção, é que as propostas apresentadas nas pesquisas com o uso das tecnologias, majoritariamente para as crianças de 5 anos, apresentam atividades voltadas para a préalfabetização ou para a alfabetização, com jogos de construir e escrever histórias ou transcrever textos, como se a criança já estivesse no ensino fundamental. Vale lembrar que os eixos que norteiam a prática pedagógica na Educação Infantil são as interações e as brincadeiras, conforme já apresentado neste trabalho.

Outro fator relevante e de destaque enfatizado nas pesquisas foi a falta de equipamentos tecnológicos, assim como a falta de formação continuada para os professores, que acabam limitando o uso das tecnologias no contexto de Educação Infantil, uma vez que os docentes ainda apresentam resistência e dúvidas acerca de como elas podem contribuir na (trans)formação do ato de ensinar e aprender. Dessa forma, ficou visível que não basta ter à disposição os aparatos tecnológicos, é importante saber como utilizá-los no contexto educacional, para, assim, favorecer a aprendizagem e o desenvolvimento da criança. Para tanto, também é preciso que os profissionais deem um passo em favor das mudanças ocorridas com as tecnologias digitais, buscando inseri-las não apenas como recursos técnicos, mas como aliados da transformação do ato de ensinar e aprender.

Foi possível perceber que, quando as tecnologias são potencializadas não só como recursos técnicos, mas como alternativas diferentes para a criança brincar e aprender, suas investigações e experiências tornam-se mais atraentes, aguçando cada vez mais sua curiosidade em experenciar e descobrir o novo, ampliando, assim, seu conhecimento. Portanto, é fundamental criar oportunidades às crianças com o uso das tecnologias digitais, não somente para demonstrar que essas ferramentas estão disponíveis nos contextos de Educação Infantil, mas para que realmente elas possam fazer a diferença na vida das crianças, transformando o ordinário em extraordinário.

Nesse sentido, esta pesquisa deixa a porta aberta para que futuros pesquisadores possam agregar com novas reflexões e estratégias acerca de como as tecnologias podem ser inseridas nos contextos de Educação Infantil, de modo que crie oportunidades para as crianças interagirem, explorarem e construírem suas brincadeiras e aprendizagens. Essas reflexões permitem (trans)formar o fazer pedagógico, rompendo com paradigmas que ainda engessam as práticas desenvolvidas na Educação Infantil.

\section{Referências}

Anjos, R. A. V. dos, Alonso, K. M. \& Anjos, A. M. dos. (2018). Infância (des)conectada e a psicopedagogia: O uso das tecnologias digitais na Educação Infantil e o impacto na aprendizagem. Revista de Educação a Distância - Em Rede, 5(1), 183-196. https://www.aunirede.org.br/revista/inde x.php/emrede/article/view/291

Araújo, C. \& Reszka, M. de F. (2016). O brincar, as mídias e as tecnologias digitais na Educação Infantil. Universo acadêmico, Taquera, 9(1), 175-191. https://www2.faccat.br/portal/sites/default/files/UA2016_o_brincar.pdf 
Araújo, L. C. et al. (2018). Jogos digitais na Educação Infantil: Contribuições para o processo de aprendizagem. III Congresso sobre Tecnologias na Educação Infantil (Ctrl+E 2018), 5-8, 461-467. http://ceur-ws.org/Vol-2185/CtrlE_2018_paper_73.pdf

Badaró, E. A. (2020). Recursos tecnológicos na Educação Infantil. Revista Científica Educ@ ção,3(5), 589-595. https://periodicosrefoc.com.br/jornal/index.php/RCE/article/view/72

Bevilaqua, A. R. (2020). Ensino remoto contingencial: A Educação Infantil na pandemia em uma escola municipal do Rio de Janeiro. Revista Carioca de Ciências, Tecnologia e Educação (online), 29-31. https://recite.unicarioca.edu.br/rccte/index.php/rccte/article/view/100

Bezerra, J. S. \& Silva, G. F. (2020). O uso das tecnologias digitais no ensino de matemática para os alunos da educação infantil. Revista Multidebates, Palmas, 4(5), 80-94. https://revista.faculdadeitop.edu.br/index.php/revista/article/view/300

Brasil (1996). Lei n. 9.394, de 20 de dezembro de 1996. Estabelece as diretrizes e bases da educação nacional. Diário Oficial da União, Brasília, 23 dez. 1996. http://www.planalto.gov.br/ccivil_03/leis/19394.htm

Brasil (2009). Resolução CNE/CEB 5/2009. Ministério da Educação. Conselho Nacional de Educação. Câmara de Educação Básica. Diretrizes Curriculares Nacionais para a Educação Infantil. Diário Oficial da União, Brasília, 18 dez. 2009. http://www.seduc.ro.gov.br/portal/legislacao/RESCNE005_2009.pdf

Brasil (2017). Base Nacional Comum Curricular (BNCC). Brasília: MEC/Secretaria de Educação Básica. http://basenacionalcomum.mec.gov.br/

Cabral, N. C. de A. et al. (2018). Jogo digital em uma proposta de sequência didática para a educação infantil: Avaliação sob o ponto de vista dos professores. Revista Carioca de Ciência, Tecnologia e Educação (online), 3(1), 1-13. https://recite.unicarioca.edu.br/rccte/index.php/rccte/article/view/31

Canaan, M., Ribeiro, L. \& Yuki, P. (2017). Tecnologias digitais e influências no desenvolvimento das crianças. Anais do Congresso Nacional Universidade, EAD e Software Livre - UEADSL, 1(8), 1-6. http://www.periodicos.letras.ufmg.br/index.php/ueadsl/article/view/12240

Clímaco, F. C. \& Magalhães, C. M. (2017). Educação Infantil, mídias digitais e práticas educativas: Caminhos cruzados, possíveis diálogos. Revista Teias, 18(50), 245-264, jul./set.: Conversas sobre formação de professores, práticas e currículos. https://www.epublicacoes.uerj.br/index.php/revistateias/article/view/28010/0

Dandaro, F., Oliveira, L. S. N. \& Paulo, K. R. de. (2019). O uso de tecnologias na Educação Infantil. E-locução, 1(16), 16. https://periodicos.faex.edu.br/index.php/e-Locucao/article/view/223

Dermeval, D. et al. (2019). Mapeamento sistemático e revisão sistemática da literatura em Informática na educação. In: Jaques, P. A. et al. (Org.) Metodologia de pesquisa em Informática na educação: Abordagem quantitativa de pesquisa. Porto Alegre: SBC. (Série Metodologia de Pesquisa em Informática na Educação, v. 2).

Freire, P. (1996). Pedagogia da autonomia: Saberes necessários à prática educativa. Paz e terra.

Kenski, V. M. (2007). Educação e tecnologias: o novo ritmo da informação. Editora Papirus.

Lebrão, L. (2020). Educação tecnológica no Ensino Infantil. Anais do CIET, EnPED, 2020 - (Congresso Internacional de Educação e Tecnologias | Encontro de Pesquisadores em Educação a Distância). https://cietenped.ufscar.br/submissao/index.php/2020/article/view/1610

Leite Filho, A. G. \& Nunes, M. F. (2013). Direitos da criança à Educação Infantil: Reflexões sobre a história e a política. In: Kramer, S., Nunes, M. F. \& Carvalho, M. C. (Orgs.). Educação Infantil: formação e responsabilidade. Papirus.

Lisboa, P. (2013). Os softwares educativos e a construção de habilidades cognitivas na pré-escola. Revista Práticas de Linguagem, 3(1), 13-22. https://www.uff.br/praticasdelinguagem/files/2013/07/13-22-OS-SOFTWARES-EDUCATIVOS-E-A-CONSTRU\%C3\%87\%C3\%83O-DE-HABILIDADESCOGNITIVAS-NA-PR\%C3\%89-ESCOLA.pdf

Martins Filho, A. J. (2020). Minúcias da vida cotidiana no fazer-fazendo da docência na Educação Infantil: Além da A4. Insular.

Minayo, M. C. de S. (2001). Pesquisa Social: Teoria, método e criatividade. (18a ed.), Vozes.

Miquelino, H. A. C. (2020). Os recursos tecnológicos e o desenvolvimento da linguagem na Educação Infantil. Anais do CIET, EnPED, 2020 - (Congresso Internacional de Educação e Tecnologias | Encontro de Pesquisadores em Educação a Distância). https://cietenped.ufscar.br/submis sao/index.php/2020/article/view/1574

Oliveira, N. M. de \& Marinho, S. P. P. (2020). Tecnologias digitais na Educação Infantil: Representações sociais de professores. RAEE - Revista IberoAmericana de Estudos em Educação, Araraquara, 15(4), 2094-2114. https://periodicos.fclar.unesp.br/iberoamericana/article/view/14068

Quintero, J. (2009). Infância e educação no Brasil: Um campo de estudos em construção. In: Faria, A. L. G., Demartini, Z. de B. F., Prado, P. D. (Orgs.). Por uma cultura da Infância: metodologias de pesquisa com crianças. (3a ed.), Autores Associados.

Reis, T. V. dos et al. (2019). Tecnologias digitais na Educação Infantil: projeto de aprendizagem com Google Maps e Google Street View. Informática na educação: Teoria \& Prática, 22(2), 125-142. https://seer.ufrgs.br/InfEducTeoriaPratica/article/view/88486

Silva, P. S. \& Esperança, J. A. (2020). Mídias digitais e Educação Infantil: construindo possibilidades pedagógicas. REVASF, Pretolina, 10(22), 536-556. https://www.periodicos.univasf.edu.br/index.php/revasf/article/view/1268

Silva, M. A. da, Macedo Filho, J. A. \& Castro Filho, J. A. de. (2017). Histórias Fantásticas: produção de textos com suporte digital na Educação Infantil. Congresso Brasileiro de Informática na Educação (CBIE 2017). Anais do XXIII Workshop de Informática na Escola (WIE 2017). http://dx.doi.org/10.5753/cbie.wie.2017.1060 
Research, Society and Development, v. 10, n. 11, e137101119421, 2021

(CC BY 4.0) | ISSN 2525-3409 | DOI: http://dx.doi.org/10.33448/rsd-v10i11.19421

Souza, A. C. S., Gomes, F. B. \& Padilha, M. A. S. (2018). Perspectivas de docentes sobre o uso da mesa educacional na Educação Infantil da rede municipal do Recife: Conteúdos e estratégias. TICs \& EaD em Foco, São Luís, 4(1), 1-33. https://www.ufpe.br/documents/39399/2403766/ SOUZA\%3B+GOMES\%3B+PADILHA+-+2017.2.pdf/b9fe0c74-108a-4a6a-8020-a01e74e5aa08

Souza, H. A., Silva, M. A. da \& Castro Filho, J. A. de. (2019). Produção e ilustração de textos com suporte D-digital na Educação Infantil. Anais do IV Congresso sobre Tecnologias na Educação (Ctrl+E 2019). https://sol.sbc.org.br/index.php/ctrle/article/view/8887 